
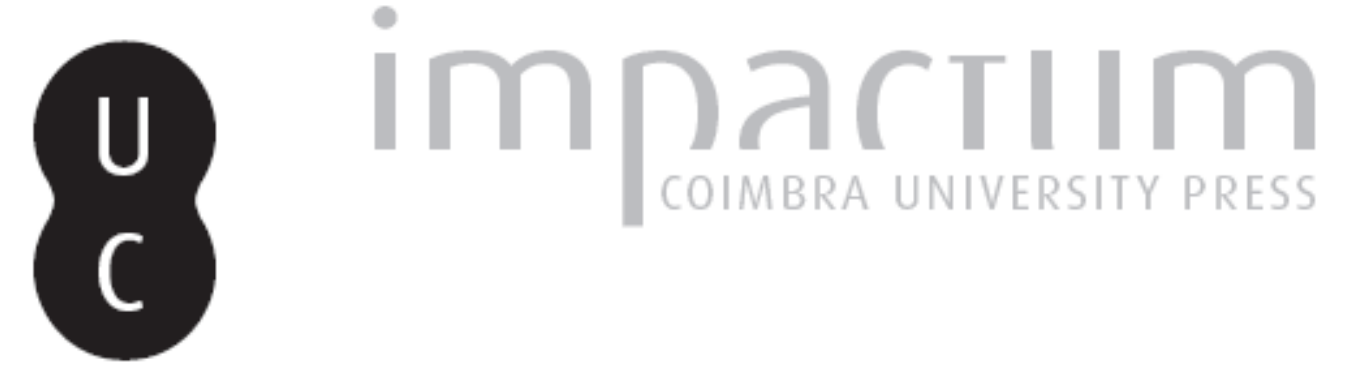

Duas ânforas romanas de Caceia: (Vila Real de Santo António)

Autor(es): $\quad$ Arruda, Ana Margarida; Frade, Isolina; Travassos, Jorge

Publicado por: Imprensa da Universidade de Coimbra

URL persistente:

URI:http://hdl.handle.net/10316.2/45600

DOI:

DOI:https://dx.doi.org/10.14195/1647-8657_26_6

Accessed : $\quad$ 26-Apr-2023 11:08:36

A navegação consulta e descarregamento dos títulos inseridos nas Bibliotecas Digitais UC Digitalis, UC Pombalina e UC Impactum, pressupõem a aceitação plena e sem reservas dos Termos e Condições de Uso destas Bibliotecas Digitais, disponíveis em https://digitalis.uc.pt/pt-pt/termos.

Conforme exposto nos referidos Termos e Condições de Uso, o descarregamento de títulos de acesso restrito requer uma licença válida de autorização devendo o utilizador aceder ao(s) documento(s) a partir de um endereço de IP da instituição detentora da supramencionada licença.

Ao utilizador é apenas permitido o descarregamento para uso pessoal, pelo que o emprego do(s) título(s) descarregado(s) para outro fim, designadamente comercial, carece de autorização do respetivo autor ou editor da obra.

Na medida em que todas as obras da UC Digitalis se encontram protegidas pelo Código do Direito de Autor e Direitos Conexos e demais legislação aplicável, toda a cópia, parcial ou total, deste documento, nos casos em que é legalmente admitida, deverá conter ou fazer-se acompanhar por este aviso. 
FACULDADE DE LETRAS

INSTITUTO DE ARQUEOLOGIA

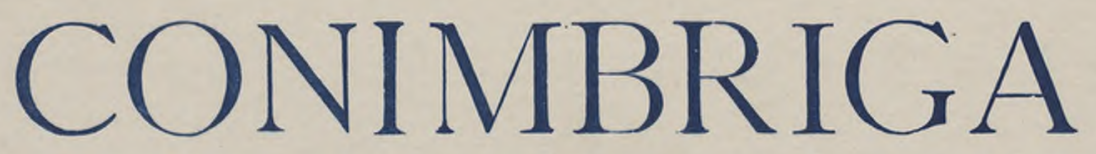

VOLUME XXVI

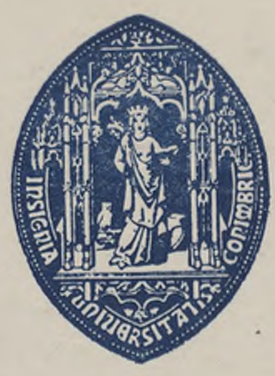

UNIVERSIDADE DE COIMBRA

1987 
Ana Margarida ARruda

Investigadora da UNIARCH (Lisboa)

ISOLINA FRADE

Professora do Ensino Secundário

JORGE TRAVASSOS

Professor do Ensino Secundário

DUAS ÂNFORAS ROMANAS DE GACELA (VILA REAL DE SANTO ANTÓNIO)

«Conimbriga», XXVI (1987), p. 125-131

Resumo: As duas ânforas aqui publicadas, provenientes de contexto subaquático, foram recolhidas na costa algarvia. Colocam questões formais e outras que se referem ao seu conteúdo.

A ânfora $n .^{\circ}$, que teria transportado defrutum, será objecto de uma particular atenção.

Discutem-se igualmente alguns problemas relacionados com o comércio do garum na bacia do Mediterrâneo Ocidental.

RÉSUMÉ: Les deux amphores publiées dans cet article proviennent de contexte subaquatique, et elles ont été récueillies sur la côte de 1'Algarve. Elles posent des questions formelles et d'autres concernant leur contenu.

L'amphore n. $^{\circ} 1$, qui aurait transporté defrutum, sera object de particulière attention.

On discute aussi quelques problèmes posés par le commerce du garum dans l'Occident méditerranéen. 
(Página deixada propositadamente em branco) 


\section{DUAS ÂNFORAS ROMANAS DE CACELA (VILA REAL DE SANTO ANTÓNIO)}

\section{Circunstâncias do achado}

Em Agosto de 1985, decorria a 3. ${ }^{\text {a }}$ campanha de escavações arqueológicas no Castelo de Castro Marim, foi a equipa da UNIARCH informada que um pescador tinha recolhido, ao largo de Caceia, duas ânforas, presumivelmente romanas, que se encontrariam na sede da Junta de Freguesia de Vila Real de Santo António.

Deslocámo-nos então àquelas instalações onde verificámos que se tratava de duas ânforas, em bom estado de conservação, incluíveis nas formas Haltern 70 e Beltrán II. Procedemos de imediato ao seu desenho, descrição e registo fotográfico.

Contactámos, de seguida, o mestre do barco, Sr. Joaquim Madeira Batista, que nos informou não poder garantir com muita exactidão o local do achado, uma vez que pescava naquelas águas pelo sistema de arrasto. No entanto, as ânforas eram seguramente provenientes da área compreendida entre Tavira e Caceia, sensivelmente a 50 milhas da costa e a uma profundidade de 320 braças. Mais nos informou que era habitual a presença de inúmeros fragmentos cerâmicos nas redes quando incidia a sua actividade naquela área.

\section{Caracterização e considerações gerais}

A ânfora $n .^{\circ} 1$ inclui-se na forma Haltern 70 . Invariavelmente englobada no tipo Dressel 7-11 ou Beltrán I, a forma Haltern 70 é reconhecida, como tipo individualizado, a partir do estudo do 
naufrágio de Port-Vendres II (Colis et alii, 1977). É também a partir daí que se abandona por completo a ideia de serem as ânforas Haltern 70 utilizadas no transporte de preparados piscícolas. De facto, as inscrições lidas nas ânforas Haltern 70 desse naufrágio indicam que defrutum era o seu conteúdo. Outras inscrições em ânforas deste tipo dizem-nos que azeitonas conservadas em defrutum eram nelas transportadas. Uma inscrição descoberta numa outra ânfora H. 70, em Amiens (Massy et alii, 1976), indica sapa como conteúdo.

A defesa feita por Parker (Parker et alii, 1981) do carácter não alcoólico do defrutum contrariou a posição assumida pelos autores do trabalho de Port-Vendres II que defendiam, pelo contrário, que defrutum poderia considerar-se um vinho, transformando, assim, as ânforas Haltern 70 em vinárias. Em 1985, Sealey defende que, para além de conservante, o defrutum é elemento que, por si só, representa um papel importante na economia romana, papel esse que só agora começa a adivinhar-se. Mais afirma que esse mesmo defrutum seria transportado sozinho nas ânforas Haltern 70. Resta-nos, pois, explicar que o defrutum - e as suas variantes sapa e caroenum é obtido pela ebulição do sumo de uva já fermentado, vulgo mosto, tendo essa ebulição o papel de impedir a continuação da fermentação, parando o processo de transformação do açúcar em álcool.

Se, em relação ao conteúdo, se gera ainda alguma polémica, quanto à origem destas ânforas a situação é mais pacífica, tudo indicando que são originárias da Bética. O seu fabrico junto a Cádis, no Cerro de los Mártires (Beltrán, 1977), está igualmente comprovado. Parece-nos importante referir que as ânforas Haltern 70 foram fabricadas em oficinas que igualmente produziam ânforas da forma Dressel 20. As análises efectuadas por Peacock (1971) apresentam uma quase total concordância de fabricos em ânforas desses dois tipos.

Cronologicamente, as ânforas Haltern 70 devem situar-se entre $60 / 50$ a. C. e 50 d. C., sendo o exemplar aqui apresentado extremamente semelhante a um de Oberaden (Beltrán 1970, p. 391, fig. 152, n. $^{\circ}$ 3), cuja datação proposta é de 25 a. C.-14 d. C. Em Portugal, este tipo de ânfora está bem representado em Conímbriga, em níveis de Augusto e Trajano (Alarcão, 1976) e no castelo de Alcácer do Sal (Tavares da Silva et alii, 1980/81). 
A ánfora agora estudada encontra-se fracturada ao nivel do bordo, medindo actualmente $108 \mathrm{~cm}$ de altura. O corpo é cilindrico, de paredes paralelas, asas de secção oval, paralelas ao colo e o pé é pequeno e cónico. A superficie externa apresenta inúmeras concreções de origem marítima, mas é visível ainda que possuía engobe de cor bege. A pasta é cinzenta alaranjada, com alguns elementos não plásticos, essencialmente grãos de quartzo e algumas inclusões de partículas brancas e negras.

A ânfora $n .^{\circ} 2$ inclui-se na forma II de Beltrán. Possui corpo ovoide, abaulado na zona inferior da pança, colo alto e cilíndrico e boca ampla com lábio de secção triangular. As asas, largas, são de secção aplanada, ligando-se ao colo muito perto da boca. Encontra-se fracturada no pé, mas o que existe deixa antever um fundo oco e cónico. Estas características fazem incluir o nosso exemplar no tipo A da forma II.

Em Portugal, são conhecidas na área urbana de Setúbal, nomeadamente na fase II B da fábrica de salga de peixe da Praça do Bocage (Tavares da Silva e Coelho Soares, 1980/1981). No castelo de Alcácer do Sal (Tavares da Silva et alii, 1980/1981) e em Conímbriga (Alarcão, 1976), os exemplares da forma II de Beltrán incluem-se no tipo B, parecendo raro em Portugal o tipo A.

As ânforas desta forma transportaram preparados piscícolas entre 25 a. C. e os finais do século $\mathrm{n}$ d. C., muito especialmente entre o último quartel do século i a. C. e os finais do século i d. C. Foram fabricadas na Bética, conhecendo-se os fornos de Cerro de los Mártires, Rinconcillo de Algeciras e Puerto Real, todos em Cádis. O exemplar de Caceia assemelha-se aos fabricados nos fornos de Puerto Real, mais exactamente aos de Villanueva e Cerro de los Mártires (Beltrán 1977).

Também a superfície externa desta ânfora se encontra repleta de concreções. A pasta é bege, possui abundantes elementos não plásticos essencialmente quartzos. 


\section{Questões finais}

É um dado adquirido a importância da Península na produção de salga de peixe para o Império. A Bética e a Lusitânia têm um papel especialmente importante, produzindo quantidades industriais. Esta situação vai originar a criação de novas formas de ânforas genuinamente hispânicas. É o caso, como vimos, dos dois exemplares agora estudados.

O aparecimento destas ânforas ao largo de Caceia levanta, no entanto, um problema, aliás já referido por Tavares da Silva e Coelho Soares em 1980/1981: como explicar a importação de preparados de peixe para regiões que os produziram e que possuíam olarias onde se fabricavam ânforas para o transporte desses produtos? Neste caso concreto, seria pertinente a questão de estas importações serem contemporâneas dos momentos imediatamente anteriores ao primeiro arranque das fábricas do litoral algarvio — sobre as quais, aliás, pouco sabemos.

\section{BIBLIOGRAFIA}

AlarCão, J., 1976 — Les amphores, «Fouilles de Conimbriga VI — Céramiques diverses et verres», p. 77-88, Paris.

Beltran Lloris, M., 1970 - Las ânforas romanas en España, Saragoça.

BeLtrán Lloris, M., 1977 - Problemas de la morfologia y del concepto histórico-geográfico que recubre la noción de tipo. Aportaciones a la tipologia de las ánforas héticas, «Méthodes classiques et méthodes formelles dans l'étude des amphores», École Française de Rome, 32, p. 97-131, Roma.

Colls, D., Étienne, R., Lequement, R., Liou, B., Mayet, F., 1977 $L$ épade Port-Vendres II et le commerce de la Bétique à l époque de Claude, "Archaeonautica», I, Paris.

Massy, J. L., Vasselle, F., 1976 - Le commerce des amphores à Amiens, «Cahiers Archéologiques de Picardie», 2, p. 153-152.

Parker, A. J., Price, J., 1981 — Spanish exports of the Claudian period; the significance of the Port-Vendres II wreck reconsidered, «Journal of Nautical Archaeology and Underwater Exploration», 19, p. 221-228.

PeAcock, D. P. S., 1971 Roman amphorae in pre-Roman Britain, «The Iron Age and its Hill Forts. Papers Presented to Sir Mortimer Wheeler», University of Southampton, Monography series, n. ${ }^{\circ} 1$, p. 161-188, Southampton. 
Sealey, P. R.-Amphoras from the 1971 excavations at Colchester Sheepen, «BAR», British Series, 142, Oxford.

Tavares da Silva, C., Soares, J., Mello Beirão, G., Ferrer Dias, L., Coelho SoAres, A. - 1980/81 -Escavações arqueológicas no Castelo de Alcácer do Sal, «Setúbal Arqueológica», VI-VII, Assembleia Distrital de Setúbal, p. 149-219.

Tavares da Silva, C., Coelho Soares, A.,1980/1981 - A Praça do Bocage (Setúbal) na época romana - escavações arqueológicas de 1980, «Setúbal Arqueológica», VI-VII, Assembleia Distrital de Setúbal, p. 249-284. 


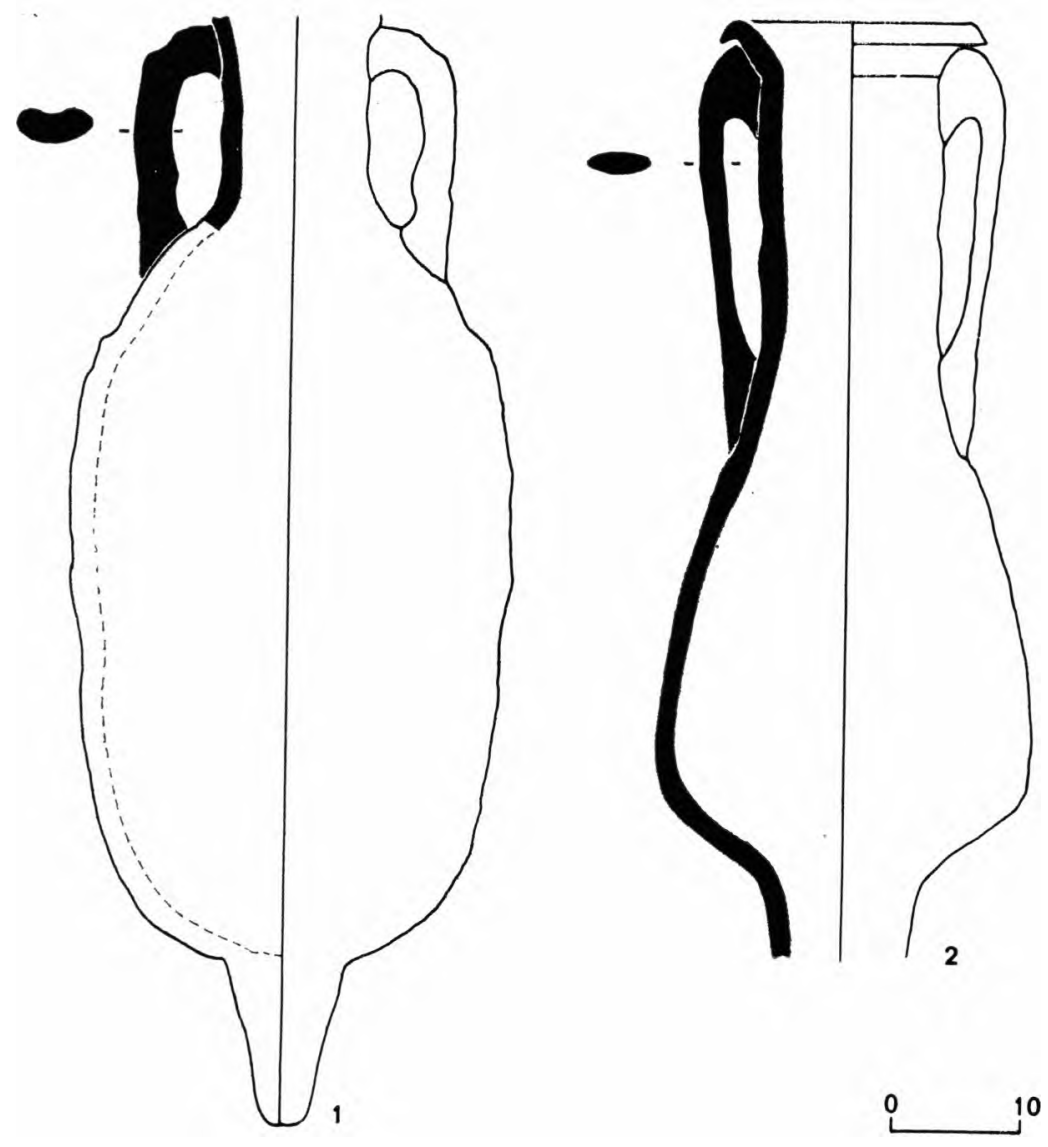

FIG. 1 